\title{
Uncovering the Reality Within Virtual Software Teams
}

\author{
Valentine Casey \\ Dept of CSIS and Lero - The Irish Software \\ Engineering Research Centre \\ University of Limerick \\ Ireland \\ 353.61 .213584 \\ val.casey@ul.ie
}

\author{
Ita Richardson \\ Dept of CSIS and Lero - The Irish Software \\ Engineering Research Centre \\ University of Limerick \\ Ireland \\ 353.61.202765 \\ ita.richardson@ul.ie
}

\begin{abstract}
To support software development globalisation, organisations are increasingly implementing virtual team strategies. However, these teams have to work within the confines of the factors which distance introduces, thus not always allowing effective coordination, visibility, communication and cooperation to take place. The successful implementation and management of such teams must be done differently to those at single-site locations.

To establish what factors significantly affect the implementation of virtual teams, the authors carried out qualitative research in two organisations in Ireland. Results from this research demonstrate that many factors are reality for those involved in global software development. In this paper we present five of these factors and discuss the impact these had on the virtual teams. These five are: use of communication tools, project management, process engineering, technical ability and knowledge transfer and motivational issues. If these are not explicitly addressed by management it can lead to serious problems.
\end{abstract}

\section{Categories and Subject Descriptors}

D.2.9 [Software]: Software Engineering - management

\section{General Terms}

Management, Human Factors

\section{Keywords}

Communication Tools, Project Management, Process Reengineering, Technical Ability, Knowledge Transfer, Motivational Issues, Global Software Development, GSD, Virtual Teams.

\section{INTRODUCTION}

In recent years the software industry has been impacted by globalisation and that trend continues today. The advent of the internet, e-mail and improved and low cost international telecommunications has facilitated the development of virtual work groups and virtual companies [22], resulting in software development being a globally sourced commodity [12]. This has

Permission to make digital or hard copies of all or part of this work for personal or classroom use is granted without fee provided that copies are not made or distributed for profit or commercial advantage and that copies bear this notice and the full citation on the first page. To copy otherwise, or republish, to post on servers or to redistribute to lists, requires prior specific permission and/or a fee.

GSD'06, May 23, 2006, Shanghai, China.

Copyright 2006 ACM 1-59593-085-X/06/0005...\$5.00 led to the migration of software development and maintenance operations to geographically distributed locations. In some cases application development and maintenance is completely outsourced to remote third party organisations. In other situations, multinational organisations have set up subsidiaries in low cost economies. During the nineties the trend was for software companies to outsource software development to third parties or subsidiaries based in Ireland and India. Currently the focus has shifted away from Ireland to Eastern Europe and the Far East where a large percentage of software outsourcing is now centred in India and Malaysia. The number of organisations globalising their software development continues to rise [12]. Ultimately this means that globally distributed software development will continue to have a significant impact on the software industry and world economy as a whole.

However, due to the level of complexity involved in software development, outsourcing is not a straightforward task [14]. Some of the difficulties encountered include such factors as the problem of understanding requirements and the testing of systems [27]. These difficulties are compounded by cultural and language differences, lack of communication, distance from the customer, different process maturity levels, testing tools, standards, technical ability and experience. The management of global software development is a difficult and complex task [10], [18].

The authors, in this paper, through research into two different organisations in Ireland, examine global software development and in particular, virtual software teams. We discuss five of the factors which cause problems in virtual team management.

\section{VIRTUAL SOFTWARE TEAMS}

To support the management of global software development, many organisations are implementing a virtual team strategy. So what is a virtual team? The virtual team is the core building block of the virtual organisation [16], [21], [7]. A traditional team is defined as a social group of individuals who are collocated and interdependent in their tasks. They undertake and coordinate their activities to achieve common goals and share responsibility for outcomes [25]. Virtual teams have the same goals and objectives as traditional teams, but operate across time, geographical locations and organisational boundaries linked by communication technologies [19]. A virtual team may be formally defined as "A team whose members use the Intranet, Intranets, Extranets and other networks to communicate, coordinate and collaborate with each other on tasks and projects even though they may work in different geographical locations and for different organisations." [22]. 
The virtual team is specifically categorised as differing from the traditional team in that it is distributed across geographical locations. Virtual teams normally operate in a multicultural and multilingual environment, which may cross-organisational boundaries [9]. The focus of this work is the operation of virtual teams in the software development environment. It is in this context and utilising the definition as outlined above the term "virtual software team" is utilised in this work.

\section{RESEARCH PROJECT}

This research on which our work is based consisted of two stages. The first stage examined virtual software teams set-up and operation in an Irish company who partnered with a US based organisation. The second stage focused on the testing environment in an Irish-based US multi-national company - this company had distributed their testing to a Far Eastern organisation, which implemented a virtual software team strategy that incorporated team members in both locations.

\subsection{CASE STUDY 1 - SFT AND STOCK EXCHANGE TRADING}

The initial case study was undertaken with an Irish based company SFT who had partnered with a large US financial organisation Stock Exchange Trading Inc. (pseudonyms), focusing on the establishment and operation of virtual software teams resulting from this partnership.

Stock Exchange Trading Inc. had an on-going requirement for the development and maintenance of bespoke financial software. Initially, all development and maintenance activities were carried out in-house. As a result of continued expansion, Stock Exchange Trading Inc. had an increasing demand for software development and maintenance, but their in-house IT strategy was becoming too expensive. The solution was to find an efficient alternative, which would leverage the experience of their existing IT department while maintaining the level of quality and support required at a cost effective price.

Initially a number of near shore outsourcing options were considered, but were rejected due to cost. Stock Exchange Trading Inc. had previously successfully outsourced their Y2K legacy code renovation to an Irish based company SFT, and this relationship was expanded into a four-year partnership. The terms outlined that Stock Exchange Trading Inc. would partner with the Irish based SFT and establish virtual software teams to undertake the development and maintenance of all its software applications. Seventy percent of the Irish team members were required to spend six to twelve months working onsite in the U.S. organisation. This allowed Stock Exchange Trading Inc. to develop complicated bespoke software within a short timeframe following the winning of a large contract. Once this project was complete the Irish team members returned home. Meanwhile, the infrastructure had been put in place and the team members who remained in Ireland had successfully provided support to their Irish and U.S. colleagues. At this stage, the virtual software teams were established and work commenced.

\subsection{CASE STUDY 2 - MULTI-NATIONAL COMPUTING US}

The company where this research was undertaken is part of a large U.S. multinational, Computing US (a pseudonym). The parent organisation embarked on a global manufacturing strategy in the nineteen sixties and has been operating in Ireland for over twenty years. The Irish software operation has been successful and has expanded over that period. A large percentage of the work undertaken has been in cooperation with the U.S. parent. The success achieved has been attributed to the development of a common corporate culture between both locations and the near shore cultural and linguistic status ascribed to Ireland [12]. Over that period the Irish company did outsource some aspects of its operation to other organisations and divisions worldwide. The outsourced work was basic and partitioned in such a manner that there was limited need for communication and coordination between locations.

In the last two years corporate strategy has changed. The company has established virtual software teams between Ireland and the Far East. The goal is to leverage the technical ability of the Irish staff with the competitive salary levels of the Far Eastern engineers. When this research was undertaken a number of virtual software teams were in operation within the Irish-based Computing US. Some had been established for over a year while others were only operating for a number of months. Given that embarking on a virtual software team strategy with a Far Eastern organisation was a new endeavour for the company, they were keen to receive any support they could.

\section{RESEARCH METHODOLOGY}

The methodology employed within Case Study 1 was the action research five-phase cyclical process based approach as defined by [26] and [1]. Action research entails the analysis of direct intervention of the researcher [11]. As this methodology facilitates the researcher as an active participant it was the most suitable approach as one of the authors held the position of software Quality Manager in SFT (one of the organisations researched) and was directly involved in the activities researched. Thus, it provided both authors with the objectivity and structure to effectively perform their work.

The authors reached collaborative agreement on what constituted the client-system infrastructure with both organizations. This allowed the research to be scoped and provided the context in which it took place. The researchers followed the steps in the five phase cyclical approach defined by [2]:

$$
\begin{array}{ll}
\text { - } & \text { Diagnosing } \\
\text { - } & \text { Action Planning } \\
\text { - } & \text { Action Taking } \\
\text { - } & \text { Evaluation } \\
& \text { Specify Learning }
\end{array}
$$

The diagnosing phase was where the underlying reasons for undertaking the research were collaboratively identified. The specific areas of concern were discussed and defined. The urgent goal was to effectively stabilise the projects. It was realised this could not be successfully achieved in the long term by instigating only cosmetic change. The overall objective was to discover how and why teams who had worked very successfully together while co-located ended up as two uncooperative and opposing factions. That stated the need to effectively identify and address-pressing problems had to be a short-term objective to achieve overall project stability. In this manner long term and short term goals were defined. 
During the action planning phase the activities to identify and address specific problems were collaboratively planned. These included deciding how best to undertake the research and implement the changes required. The effectiveness of these changes had to be assessed and further corrective action taken when deemed necessary. Direct observation, interviews and focus group discussions were planned. It was agreed that future iterations of the cycle would address the long-term objectives of the research.

The next stage was the implementation of the action taking phase where the activities outlined during the action planning stage were implemented. Corrective action was identified and implemented. Once this had taken place a collaborative evaluation was carried out and the effectiveness of the corrective activities employed were determined. This was followed by the specify learning phase, where the lessons learned from the research were discussed with the management of both organisations. Where required this information was utilised to amend organisational processes and procedures to leverage this knowledge. It was also used by the researchers to evaluate and validate the research carried out. The outcome of the initial iteration was the projects were effectively stabilised. After addressing these basic problems a key objective was to prevent their reoccurrence. The next step was to identify the root causes and specific events or actions that had triggered the problems experienced. This was achieved by undertaking a second iteration of the research cycle.

In Case Study 2, we selected the participant observational research approach [4]. Onsite access with the Irish based U.S. multi-national company was negotiated and agreed. Research questions were defined and formulated [15]. Onsite qualitative research included document review, observation, interviews and questionnaire completion. The on-site aspect of the research allowed close observation of the teams and organisation in operation while being a non-participant in the day-to-day activities of the company. It also facilitated the development of a level of trust between the researchers and the staff and management of the organisation, which was reflected in the candid responses received during interviews.

Using content analysis, data was summarised, displayed and analysed and conclusions were drawn and verified [20]. We identified key factors which have a specific relevance to virtual software team operation. Five of these factors are presented in Section 5, each one is illustrated with at least one example from the cases we studied.

\section{VIRTUAL SOFTWARE TEAMS IN OPERATION - LESSONS LEARNED}

The virtual software team environment by its very nature is complex and dynamic [24] (See Figure 1). Distance in itself introduces barriers and complexity. The need for effective coordination, visibility, communication and cooperation are key variables for success [6], [17]. However, these are negatively impacted by distance and this increases the barriers and complexity faced by those managing virtual software teams.

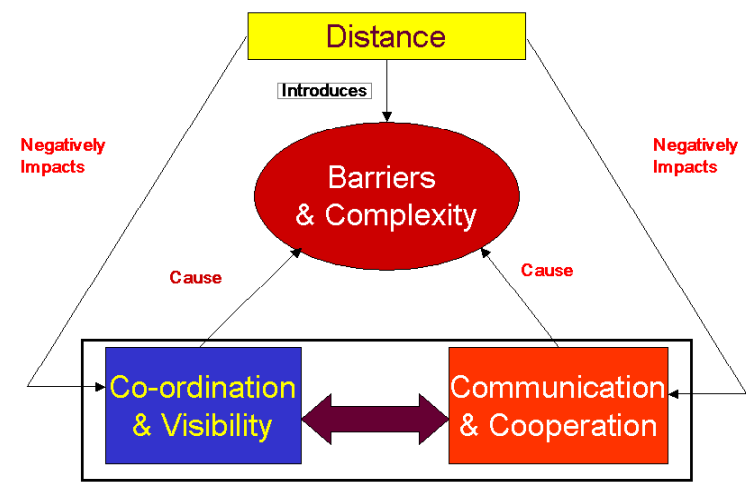

Figure 1. Virtual Software Team Environment

\subsection{Use of Communication Tools}

For successful global distribution of software development, "communication methods and tools offer one of the most powerful and effective ways to gather and disseminate information and control projects" [17]. However, as we observed during our research, the misuse of communication tools can cause problems.

This was highlighted when we observed the day-to-day operation of e-mail in both studies. While e-mail was used to communicate, it was also used as a weapon to publicly attack fellow team members. The practice of copying senior management on minor problems, which were caused by team members at the other location, was widespread. One respondent stated "Developer A (at the other location) would always copy. If you asked them what time it was they would copy the reply to your manager." Both groups were equally guilty of employing this tactic. While this activity highlighted the problem, it alienated the individual towards whom it was directed. It also had a negative impact on fellow team members at that location, who saw it as an attack on the group as a whole. This situation was further compounded by management reacting to these e-mails and getting involved with minor issues which should have been addressed by the relevant team leader. It was noted that when management responded, they normally took the side of individuals where they were located. This further alienated and added to the mistrust felt by people at the other site.

The solution provided was a documented e-mail procedure in which guidelines were agreed stating when, how and to whom problems should be highlighted. There were three levels of reporting - team leader to project manager to senior management at both locations. Following the change in procedure very few minor issues were raised with the project managers and none had to go to senior management for resolution.

Furthermore, we examined why the problem had arisen. Distance and the lack of the opportunity for informal communication played a part. Misuse of communication tools were a contributing factor to the conflict, alienation, mistrust and lack of co-operation which existed between team members working at different locations. 


\subsection{Project Management}

Project management of global teams is different to that of local teams. "The complex, usually uncertain, and highly interdependent nature of project tasks, together with geographical, temporal, structural and cultural gaps fundamental to distributed teams, make management of virtual projects a relatively complex undertaking" [24]. When virtual teams are set up, management need to take this complexity into account.

In Computing US (Case Study 2), the project management strategy implemented by the Irish-based organisation carrying out virtual software team testing with their Far Eastern partner proved less then optimal. This was despite the fact that in previous outsourcing endeavours the organisation's project management had been considered adequate. As a result there were specific issues that needed to be addressed. The problem was researched and two relevant factors were identified. Previously, the organisation had only undertaken outsourcing projects where effective partitioning of work had taken place [13]. This effective partitioning had ensured there was limited need for communication and coordination between sites. The second factor identified was the nature of the work itself which was straightforward and required only basic technical skills to be executed correctly. Limited external supervision and minimum interaction between staff at both locations was required. Where only straightforward outsourcing had been undertaken a single site, project management strategy at both locations proved successful. As one respondent stated: "When we outsourced before we only sent over basic 'grunt' work that required very little collaboration on our part”.

In the light of the needs of the virtual software team, project management had to be reassessed - "I would have a good process, which was well defined and followed with clear roles, well coordinated." - the implication from this respondent was that these key elements were not in place. There was the requirement to plan, monitor and control cost, time and quality in each project. However, in addition, there was also the need to plan, implement and monitor communication and coordination related activities with effective policies and procedures. The impact of cultural diversity on the operation of the projects had to be determined, monitored and addressed. A coherent team who were required to work as a single unit to achieve specific testing goals had to be developed from a geographically dispersed group [3]. Policies and procedures needed to be drawn up for the establishment and operation of the virtual software teams that ensured visibility into their activities and operation at both locations, including roles and responsibilities.

To be effective a successful virtual software team project management strategy should address monitor and control all these additional variables and areas.

\subsection{Process Reengineering}

Within the virtual software team environment, it was imperative that processes were defined tightly. As [5] states - "A well understood development methodology leads to a working relationship in which many of the old coordination conversations are no longer needed. The development process is understood and agreed on by all".
In both case studies the need for process reengineering was identified. While effective for single site development and maintenance, the processes employed proved inadequate for a virtual software team environment. In case study 1 the process was seen as being imposed and the sole property of the staff of Stock Exchange Trading Inc. This respondent statement reflects the feelings of many of the team members - "We exported the Irish process out to them and there was no negotiation". Team members based in SFT while having relevant suggestions for process improvement were not consulted and any suggestions they made were ignored. This added to the alienation being experienced by the Irish staff. A similar situation was identified in case study 2 .

To address the process issues, the need for establishing common goals, objectives and rewards were identified. The process had to be totally reengineered to incorporate these issues. A common vocabulary with clear definitions of artefacts, deliverables and milestones was jointly formulated. These were incorporated into the development of a shared and agreed process, which specifically addressed the needs of the virtual environment in which it operated. The input of staff at both locations was encouraged and valued.

\subsection{Technical Ability and Knowledge Transfer}

Embarking on a global software development strategy should bring benefits to the organization. However, "without effective information and knowledge-sharing mechanisms, managers cannot exploit GSD's benefits" [14]. Our research has demonstrated that this does not happen by 'osmosis' - strategies need to be put in place to ensure that this happens successfully. As our research demonstrates, even where such strategies are put in place, they may not always be successful.

In Computing U.S. (Case Study 2), there was a clear difference in the level of technical ability between the Irish based staff and their Far Eastern colleagues. The Irish operation was well established and the majority of staff were honours graduates in software related fields. The average experience level of the Irish team members was four years, most of it gained within the organisation's testing department. Through their continuous staff training programme new employees had one to one mentoring, bolstered by continuous in-house technical training. The Irishbased teams competitive advantage lay in a combination of their technical and practical experience.

The Far Eastern organisation to which they outsourced had been in operation for two years and had been assessed as Capability Maturity Model (CMM) level 5. During that period they carried out straightforward, well-partitioned [13] outsourced software testing. The company grew from a staff of 30 to 100 in eighteen months. It was to be expected that there would be mixed technical skill levels within the organisation as a result of this rapid expansion. However, a large number of the new starts were graduates, or had limited testing experience. They did not have the opportunity to gain the level of technical expertise required for undertaking complex virtual software team testing. The existing experienced Far Eastern staff were also limited in their exposure to complex testing given the nature of the work they had previously carried out. This limited level of experience required training and knowledge transfer between Ireland and the Far East 
to ensure successful implementation of the virtual software team strategy.

To facilitate knowledge transfer Irish-based mentors were provided for Far Eastern team members. In reality given the time zone difference and the limited use of synchronous communication tools this had its limitations. A trainer travelled from Ireland to the Far East to provide formal training. Remote online training was also introduced. The trainer's assessment was "A lot of them had very little experience and were just fresh from college or fresh from another job in a different sector or different company." In the Far Eastern organisation there was limited technical knowledge and linguistic and cultural problems were encountered. The knowledge of English within the Far Eastern organisation was very varied. The ability to communicate effectively is key to team based success. The ability to understand the trainer's language is paramount. It was also very difficult to assess the effectiveness of the training provided, as there was very little feedback received from the Far Eastern participants.

Shortly after the training had been provided, some of the remote participants visited Ireland. When they encountered some of the issues and technologies they had recently received training in they stated they had no knowledge of these areas and it was the first they had heard of them. One of the key problems identified was the participant's willingness to say yes to everything even when they did not understand what had been presented. A respondent in this research stated "I asked where people worked and these two guys worked in technology X and I thought they were experts in technology $\mathrm{X}$ they had worked there for the last two years. It turned out they knew very little about it".

There was also the added factor that the Irish team members were very worried about the future of the Irish operation. A policy of imposing a recruitment embargo in Ireland while actively recruiting in the Far East did little to reassure Irish staff. These factors directly reinforced the fears of the Irish staff and reduced the level of trust between locations. It caused difficulties when it came to mentoring and sharing knowledge with remote team members - "The problem with it is there is reluctance within the team... So some people are a bit slow to share some of the knowledge they have ... People are hesitant to transfer knowledge, it is human nature".

Due to the importance of knowledge transfer and training to the success of the virtual software team strategy, management of the teams should have had access to information on the technical and academic ability of all team members. This could have been provided through a skills database. Knowledge of technical ability would have impacted positively on both locations. For example, when a team member required a subject matter expert for technical support it would have proved useful. Lack of knowledge transfer was also caused through fear of losing jobs.

\subsection{Motivational Issues}

Motivation is defined in the organisational setting as referring "to the mainspring of behaviour; it explains why individuals choose to expend a degree of effort toward achieving particular goals" [8]. Without the motivation of all team members within a virtual software team, it is difficult to work together as a unit. Therefore the full benefits of global software development will not be achieved. In the research we carried out, motivation was a major issue for many employees.

In case study 1 , once the virtual software teams were set up, seventy percent of the Irish team members spent over six months working onsite in the U.S. organisation. After this time, the Irish team members returned to Ireland. Meanwhile the virtual software team infrastructure had been put in place and the team members who remained in Ireland had successfully provided support to their Irish and US colleagues. Soon serious problems started to arise. People who worked together very successfully while co-located were now actively obstructing and blaming each other for all the problems that arose during projects. It was obvious that team members were now aligned by geographical location and there was a very clear "we verses they" culture [23]. The main question posed was - how had teams, that worked effectively when they were co-located, deteriorated into opposing groups? We identified motivation as a major contributing factor. While team members were co-located in the U.S., the American team members did not comprehend the full implications of the virtual software team strategy. Once the virtual software teams were established the full negative impact on their day-to-day work, promotion and future employment prospects became clear. Management reinforced these negative aspects by utilising the strategy to justify maintaining salaries at there current levels. The effect was unmotivated people who directed their hostility toward their fellow team members in Ireland. This manifested itself in a lack of cooperation, alienation and on occasions out right obstruction when the opportunity arose. This was met with a similar negative reaction from the Irish side, who felt that if this was how the Americans worked it would be more effective to move the whole operation to Ireland.

The only effective strategy available was to make it clear to staff at both locations: if utilising virtual software teams was not an option the only feasible economic alternative was outsourcing the whole operation to the Far East. The options had to be made clear, work as a team regardless of location, or find new positions elsewhere. This was a drastic approach, but the seriousness of the situation warranted it and there was no alternative if the virtual software team strategy was to continue. This, along with the other measures outlined, helped to establish a productive working relationship between sites and facilitated the completion of projects on time and within budget for the lifetime of the contract.

Similarly, in case study 2 the same motivational issues were identified. The effect of using the virtual software team strategy to motivate the Irish team members by stressing how cheap the Far Eastern engineers were was counter productive. Fear of job loss was a direct barrier to team motivation. When questions regarding the future of the Irish operation were raised the reply changed from "The future of the Irish operation is secure" to "Who knows what the future holds?". To address these serious issues, senior management reinforced corporate commitment to the Irish site, provided training to up skill staff at both locations and clearly communicated the benefits of the virtual software team strategy to Irish management and staff.

\section{ESTABLISHING VIRTUAL SOFTWARE TEAMS}

In this paper we have discussed five factors which should be of concern to those setting up virtual software teams. The studies 
presented were undertaken independently and at different times. The companies researched were both divisions of separate multinational organisations. Their Irish operations were of different sizes and in different locations. While both were developing and testing software, their products were targeted at different sectors. The common theme other than being located in Ireland was: they both employed virtual software teams in their software development process. Our research highlighted similar issues as directly impacting the operation of virtual software teams in each organisation.

In this paper, while we identified five factors of concern, we also present potential solutions to these concerns:

- Document communication procedure

- Project management virtual team software strategy

- Establish common goals, objectives and rewards

- Implement training and mentoring

- Managerial commitment to location.

We found communication tools being used as weapons to attack fellow team members in other locations. In other situations their use was being avoided or minimised to hinder knowledge transfer. This misuse of communication tools helped to develop and perpetuate an adversarial "we verses they" culture within the teams. To facilitate effective communication we identified the need for specific training in methods of communication for all locations involved in the operation of virtual software teams. There was a specific requirement for a documented communication procedure to be drawn up and implemented.

The role of a project manager in the virtual software team situation is not simply to manage, monitor and coordinate team activities and artefacts as it is in the single site environment. To be effective a successful project management virtual software team strategy must address the specific needs of this dynamic environment. The process employed must also take account of the globally distributed nature of virtual software teams. In both cases the export of a single site process to the global environment was not successful prior to amendment.

There can be clear differences in the technical ability between Irish-based team members and their colleagues in the Far East and measures can be taken to address this. These include the implementation of common goals, objectives and rewards across sites. These differences arise because staff recruited in Far Eastern locations have had limited opportunities to gain experience in specific technologies. This is due in no small part to the fact that in a number of these countries the establishment of a software industry is at an early stage. And to the type of work which has traditionally been outsourced to these locations. This situation is changing and in the future this will cease to be such an important issue. The trend is that more complex projects are being outsourced to these locations and that the utilisation of virtual software teams for software development will become the norm.

Consequently successful knowledge transfer is essential in achieving effective virtual software team operation. Training programs need to be developed and implemented that meet the specific needs and requirements of this environment. An additional effective approach is one to one mentoring. Mentoring in a globally distributed situation is different to that carried out in a single site environment. These need to be recognised and addressed. With effective monitoring, motivation, support tools and process, organisations can successfully employ effective training and mentoring.

The fifth factor we discussed was motivation. This is an important issue in the operation of an effective virtual software team environment. Outsourcing to another location has the effect of generating fear in the staff and management where the outsourced work was taken from. If the goal is to export jobs senior management must recognise that the resulting fear and lack of motivation will impact directly on the level and quality of knowledge transfer that takes place.

On the other hand the objective may be to implement a sustained virtual software team strategy to leverage the technical experience of staff at one location with the availability of competitive cost engineers in another. It is essential to recognise and understand the debilitating impact fear has on all aspects of the operation of virtual software teams. Outsourcing should never be used as a method of controlling cost in one location. Where it is used in this way it can be counter productive and end up demotivating staff. Senior management also need to clearly demonstrate their commitment and support for personnel in all locations. Staff and management should be directly informed and should understand the overall benefits of implementing a virtual software team strategy. With regard to the staff at the site from where the work is outsourced, if possible there should be clear senior managerial commitment to that location. There should also be continued investment in training to up-skill staff to effectively undertake the new roles required by a virtual software team strategy.

\section{CONCLUSION}

In both case studies presented, inductive qualitative research was undertaken. Our goal at all times was to evaluate each case study on its own merits and determine the key factors which facilitated and impacted virtual team software development and testing in each situation. In these circumstances the uniformity in the areas highlighted by this research should in our view be of particular interest to academia and industry alike. We suggest that the factors discussed are not given the level of importance in the published literature in the GSD field that our research would suggest they warrant. For example, we are continuing our research and are examining the measurement of communication to establish whether better and more effective communication can improve the quality of the software product developed by virtual software teams.

\section{ACKNOWLEDGMENTS}

This research has been supported by the Science Foundation Ireland Investigator Programme, B4-STEP (Building a BiDirectional Bridge Between Software ThEory and Practice) and by Science Foundation Ireland cluster project, GSD for SMEs.

\section{REFERENCES}

[1] Baskerville Richard L., Distinguishing Action Research from Participative Case Studies, Journal of Systems and Information Technology, Volume 1, Issue 1, Pages 25 - 45 (March 1997)

[2] Baskerville Richard L., Investigating Information Systems with Action Research, Communications of the Association for Information Systems, Volume 2, Article 19 (October 1999) 
[3] Battin, R.D., et al., Leveraging Resources in Global Software Development. IEEE Software, 2001. 1(2): p. 70 - 77.

[4] Bryman, A. (1988) Quantity and Quality in Social Research, Routledge, London.

[5] Carmel, E. (1999) Global Software Teams: Collaboration Across Borders and Time Zones, Prentice Hall, Saddle River, NJ.

[6] Carmel, E. and R. Agarwal, Tactical Approaches for Alleviating Distance in Global Software Development. IEEE Software, 2001. 1(2): p. 22 - 29.

[7] Davidow, W. H. and Malone, M. S. (1992) The Virtual Corporation, Edward Brulingame Books/Harper Business, New York.

[8] Dawson, S. (1992) Analysing Organisations, The Macmilland Press Ltd, London, UK.

[9] DeSanctis, G., Staudenmayer, N. and Wong, S. S. (1999) Interdependence in Virtual Organisations, The Virtual Organization (Trends in Organizational Behavior) John Wiley \& Sons, Chichester.

[10]Ebert, C. and P. De Neve, Surviving Global Software Development. IEEE Software, 2001. 1(2): p. 62 - 69.

[11]Gill John, Johnson Phil, Research Methods for Managers, Second Edition, Paul Chapman Publishing, London UK (1997).

[12]Hayes Ian S., Ready or Not: Global Sourcing is in Your IT Future. Cutter IT Journal, 2002. 15(11): p. 5 - 11.

[13]Herbsleb, J. D. and Grinter, R. E. (1999) In 21 st International Conference on Software EngineeringIEEE Computer Society Press, Los Angeles, California, United States, pp. 85 - 95.

[14]Herbsleb, J.D. and D. Moitra, Global Software Development. IEEE Software, 2001. 1(2): p. 16 - 20.

[15]Holliday, A. (2002) Doing and Writingh Qualitative Research, Sage Publications, London.

[16]Jarvenpaa, S. L. and Ives, B. (1994) The Global Network Organization of the Future: Information Management Opportunities and Challenges, Journal of Management Science and Information Systems, 10, 25 - 57.
[17]Karolak, D. W. (1999) Global Software Development: Managing Virtual Teams and Environments, IEEE Computer Society Press, Los Alamitos, CA, USA.

[18]Lanubile, F., Damian, D. and Oppenheimer, H. L. (2003) Global software development: technical, organizational, and social challenges, SIGSOFT Software Engineering Notes, 28, $1-4$.

[19]Lipnack, J. and Stamp, J. (1997) Virtual Teams: Reaching Across Space, Time And Originating With Technology, John Wiley \& Sons.

[20]Miles, M. B. and Huberman, M. A. (1994) Qualitative Data Analysis: An Expanded Sourcebook, Sage Publications, London.

[21]Mohrman, S., Albers (1999) The Context for Geographically Dispersed Teams and Networks, The Virtual Organization (Trends in Organizational Behavior) John Wiley \& Sons, Chichester.

[22]O'Brien James A., Management Information Systems Managing Information Technology in the Business Enterprise. 6 ed. 2002: Mc Graw Hill Irwin.

[23]Oppenheimer, H.L. Project Management Issues in Globally Distributed Development in ICSE Workshop on Global Software Development, 2002.

[24]Paré, G. and Dubé, L. (1999) Virtual teams: an exploratory study of key challenges and strategies in Proceeding of the 20th International Conference on Information Systems, Association for Information Systems, Charlotte, North Carolina, United States, pp. 479 - 483.

[25]Powell, A., Piccoli, G. and Ives, B. (2004) Virtual Teams: A Review of Current Literature and Direction for Future Research, The DATA BASE for Advances in Information Systems, 35, 6 - 36.

[26]Susman G. \& Evered R., An Assessment of the Scientific Merits of Action Research, The Administrative Science Quarterly, Vol. 23, Issue 4. Pages: 582 -603 (1978)

[27]Toaff Shermaria S., Don't Play with "Mouths of Fire" and Other Lessons of Global Software Development. Cutter IT Journal, 2002. 15(11): p. 23 - 28. 